\title{
Editorial
}

\section{Hollywood beckons...}

Journal of Revenue and Pricing Management (2015) 14, 71. doi:10.1057/rpm.2015.12

Would you pay more to see American Sniper or Lord of the Rings? The movie industry, like the airlines is facing many challenges. They are challenged by the pay per view satellite channels and the internet. Today, you could probably watch any new movie anywhere at any time so why go to a movie theatre. In order to meet these challenges movie theatres are adopting Revenue Management practices. The purpose of Choi and colleagues' research is to examine consumers' reactions to such a pricing strategy. In addition, the authors are interested in understanding how various framing effects (surcharge versus discount) and fencing strategies (for example, differential pricing based on the time of the day) influence consumers' price fairness perceptions. The findings of this study will provide movie industry practitioners with useful insight into their pricing. Airlines are always searching for ways to maximise revenues in the hyper-competitive environment that they exist in. Weatherford notes that airlines use the sophisticated Passenger Origin-Destination Simulator simulator to examine the revenue impact of four levels of forecast multipliers (FM) in combination with three different methods of unconstraining - Expectation Maximization, Projection Detruncation and Booking Curve. Weatherford technical paper concludes airlines in a fully/semi-restricted fare environment should implement the FM approach. Revenue management and customer relationship management (CRM) are the standard strategies of many hotels to increase their profitability. Vaeztehrania and colleague consider intergration of these approaches from a practice perspective focusing on capacity allocation and overbooking decisions considering CRM strategies over a hotel network.

The history of Revenue Management is defined by the characteristics of the airline industry, but its futures lies beyond this horizon. Many developers of Revenue Management think the future application can be based on an airline approach. How wrong they are. Currie argues that different industries have different characteristics, thus Revenue Management has to go beyond the airline industry for success. Has Revenue Management really made all the difference to the airline industry? How much is fact or is it fiction? The revenue management concept seems economically logical, the direct impact on the financial result of the airline is difficult to prove. In addition the details of implementing revenue management are often hardly understood by executive management. Westermann considers some of the practical aspects in order to ensure that the performance of revenue management does not diminish over time. Fiig and colleagues review the role of distribution in Revenue Management in the airline industry over the last 50 years, describing the evolution of these systems and providing evidence for their interdependence. However, whatever the future maybe the fundamental role of distribution remains unchanged. Distribution supports the airline Revenue Management System by mediating the flow of contextual information from the customer to the airlines.

Ian Yeoman Editor

E-mail: ian.yeoman@vuw.ac.nz 